S U M A R I O

Alicia Ortega y Susana Rosano. Mapas e itinerarios en los imaginarios

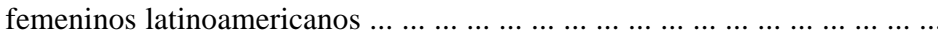

\title{
I. CicATRICES
}

Ana María Amar Sánchez. Narraciones femeninas de memoria y resistencia. Política y ética en la literatura latinoamericana en el fin del siglo xx ... ...

Silvia Sitta. Sandra Ramos: la vida no cabe en una maleta ... ... ... ... ... ...

Beatriz González Stephan. La in-validez del cuerpo de la letrada: la metáfora

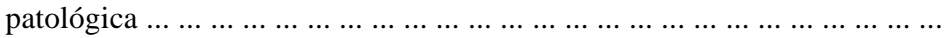

Adela Pineda Franco. La que mata y la que muere por segunda vez: algunas escenas del imaginario amenazado del porfiriato $\ldots \ldots \ldots \ldots \ldots \ldots$

23

35

\section{De La FASCINACIÓN}

Graciela Batticuore. La cultura del trato o la casa del alma. Mariquita

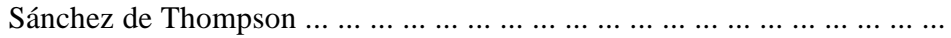
SAmuel Monder. De la seducción y otras miradas. La institución delflirten los Recuerdos de Viaje de Eduarda Mansilla

\section{I TINERARIOS}

Humberto E. Robles. Representación de la mujer en dos escritores ecuatorianos

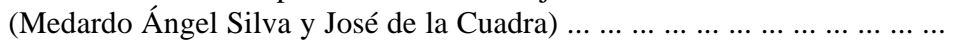

Barbara Dröscher. Orfandad. Configuraciones de una figura en la literatura escrita por mujeres en Centroamérica (1975-2000) ... ..................

Michael Handelsman. Las mujeres también cuentan en el Ecuador: reflexiones sobre tres antologías recientes de narradoras ecuatorianas y el lugar que éstas ocupan en el imaginario nacional $\ldots \ldots \ldots \ldots \ldots \ldots \ldots \ldots \ldots \ldots \ldots \ldots$

\section{Memorias de la Nación}

Márgara Russotto. Propuestas de cultura: visiones de Costa Rica en las escritoras de la modernidad centroamericana (Yolanda Oreamuno, Eunice Odio, Carmen Naranjo) 
Susana Z anetti. Memoria y memorial en Doña Inés contra el olvido de Ana

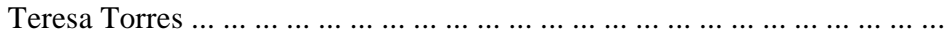
JuAn Pablo Dabove. Claudicaciones de la razón letrada y romance nacional totalitario: sobre Cola de lagartija de Luisa Valenzuela .... ... .............

\section{INTERIORES}

Gloria Medina-Sancho. El infarto del alma de Diamela Eltit y Paz Errazuriz:

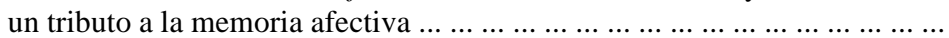
Maria Lúcia dal FarRa. Pergaminos do femenino (sobre Manuscritos de Felipa, de Adélia Prado)

\section{SeXualidades}

Florence Baillon. En diciembre llegaban las brisas de Marvel Moreno, cuerpo a cuerpo, la desvalorización de la sexualidad femenina .............

Susan Canty Quinlan. Revisando/revisualizando gêneros: A noite escura e mais eu e Invenção e memória de Lygia Fagundes Telles ... .................

Teresa Peña-Jordán. Cimarrona como la noche: cuerpos y espacios en $L a$ noche de Mercedes, de Maruja Candal Salazar ... ... ... ... .................

\section{NeCROLÓGICAS}

María Rosa Olivera-Williams, El vuelo de la reina: Marosa Di Giorgio

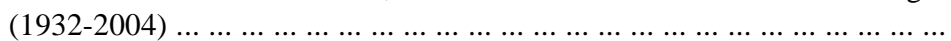

Ignacio M. Sánchez Prado, Leopoldo Zea (1912-2004): Trascender la

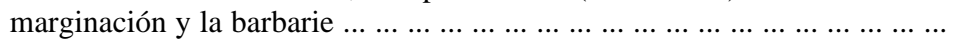

Raúl Bueno, Jorge Cornejo Polar (Arequipa 1930-Lima 2004) ... ... ... . . . . ...

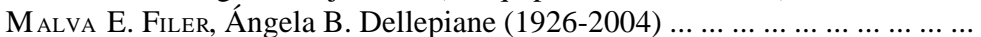

\section{RESEÑAS}

Analía Costa sobre Elena Altuna, El discurso colonialista de los caminantes $($ siglos XVII-XVIII) $\ldots \ldots \ldots \ldots \ldots \ldots \ldots \ldots \ldots \ldots \ldots \ldots \ldots \ldots \ldots \ldots \ldots \ldots$

Silvia D. Spitta sobre Lucía Melgar y Gabriela Mora, Elena Garro: lectura múltipe de una personalidad compleja $\ldots \ldots \ldots \ldots \ldots \ldots \ldots \ldots \ldots \ldots \ldots \ldots$ CRistián SANTibáñez YÁnez sobre George Yúdice, El recurso de la cultura. Usos de la cultura en la era global ........................................

Karina Galperín sobre Josiah Blackmore, Manifest Perdition. Shipwreck Narrative and the Disruption of Empire ... ...............................

María Dolores B ravo Arriaga sobre Carlos Jáuregui, Querella de los Indios en las Cortes de la Muerte ... ................................................. 